\title{
$\mathrm{R} C \& \mathrm{C}$
}

\section{OS POSTULADOS DE AUDITORIA NA ESCOLA UNIVERSITÁRIA INGLESA: UM CRUZAMENTO PERFEITO ENTRE A SOCIEDADE E A AUDITORIA}

\section{THE POSTULATES OF AUDITING AT THE ENGLISH UNIVERSITY: A PERFECT CROSS BETWEEN SOCIETY AND AUDITING}

Recebido em 03.03.2015 | Aceite final em 19.08.2015 |

Nota: este artigo foi aceito pelo Editor Jorge Eduardo Scarpin e passou por uma avaliação double blind review

A reprodução dos artigos, total ou parcial, pode ser feita desde que citada a fonte.

\section{BRUNO JOSÉ MACHADO DE ALMEIDA}

Doutorado em Ciências Económicas pela Universidade Complutense de Madrid I Professor do Instituto Superior de Contabilidade e Administração de Coimbra | Praceta Flávio Rodrigues, n.o 1, Lote B, 4음 Dto., 3000-550 Coimbra, Portugal I Telefone (00351) 919706054 | Email: brunojmalmeida@gmail.com |

\section{RESUMO}

O objetivo deste trabalho é analisar a evolução da linha do pensamento dos autores ingleses, Sherer e Kent e Flint, no que concerne às suas propostas para dotar a auditoria de uma estrutura concetual própria, à semelhança da contabilidade financeira. A contabilidade e a auditoria têm um ponto de convergência comum: o referencial contabilístico. Tanto os preparadores da informação financeira como os auditores visam construir e validar o true and fair view. Para conseguir este desiderato os autores supracitados conceberam dois sistemas postulacionais. Para analisar as suas similitudes e divergências recorremos a uma metodologia apropriada, assente numa base normativa e com o mínimo de apoio empírico e formulámos hipóteses que nos permitem concluir que a auditoria, no Reino Unido, é considerada um importante elemento de controlo externo e social das relações de accountability estabelecidas nas empresas e nas organizações, e que os sistemas postulacionais propostos representam a evolução natural das conceções de auditoria existentes naquela sociedade.

Palavras-chave: auditoria, accountability, postulados, sistema postulacional, true and fair view. 


\begin{abstract}
The aim of this study is to analyse the evolution of the line of thought of the English authors, Sherer and Kent and Flint, regarding their proposal to provide auditing with its own conceptual structure, as in financial accounting. Accounting and auditing have a point in common: the accounting standards. Both those who prepare the financial statements and the auditors aim at constructing and validating a true and fair view. For this purpose, the authors mentioned above have conceived two postulate systems. To analyse their similarities and differences, we have used an appropriate methodology which rests on a normative basis with a minimum empirical support and we have formulated hypotheses which enable us to conclude that auditing in Great Britain, is considered an important element of the external and social control of accountability relationships established in the companies and organisations, and that the postulate systems represent the natural evolution of the notion of auditing already present in this society.
\end{abstract}

Keywords: auditing, accountability, postulates, postulate system, true and fair view.

\title{
1 INTRODUÇÃO
}

Os sistemas postulacionais concebidos por Sherer e Kent (1983) e Flint (1988) surgiram numa fase de desenvolvimento da auditoria que Porter, Simon e Hatherly (1995) designaram por socio economic development. Durante este período a influência social e económica das empresas cresceu exponencialmente, com efeitos evidentes nas comunidades locais, das quais a própria organização empresarial faz parte. Dada a sua influência e poder sobre a sociedade, começou a desenvolver-se a ideia de que as administrações das empresas estão numa relação de responsabilidade social e pública para com todos os stakeholders. De facto, a sociedade ganhou consciência do impacto das decisões empresariais na envolvente, ao nível da biosfera, do investimento, do emprego e do consumo, surgindo a necessidade de se adotar uma estratégia de prevenção relativamente à poluição, à proteção dos consumidores, etc.

Neste espírito, as agências governamentais inglesas criaram uma estrutura complexa regulatória para disciplinar e normalizar as responsabilidades dos managers e a prestação de contas. Com efeito, o Companies Act $(1985$, p. 238) preconizava uma prestação de contas, baseada em demonstrações financeiras, relatório de direção e parecer de um auditor, dirigida a um largo espectro de utilizadores. Esta posição referida por Porter, Simon e Hatherly $(1995$, p. 26) está refletida no princípio fundamental da auditoria externa: a regra do accountability. Neste período, assistiu-se a um desenvolvimento acentuado das técnicas de auditoria, que, segundo Lee (1996), abrangiam a procura de evidências de uma grande variedade de fontes, tanto internas como externas, de sistemas de informação e a criação e desenvolvimento da auditoria baseada no risco. Simultaneamente, ocorreram mudanças profundas na abordagem das responsabilidades dos auditores, que refletem o seu crescente papel como um elemento importante na relação de prestação de contas, pela segurança que facultam ao processo.

A sociedade, por volta dos anos 80 do século $X X$, já exigia aos auditores uma maior intervenção na prevenção e deteção de fraudes nas empresas e no reporte, de uma maneira mais explícita, na problemática da continuidade da empresa. Aumentou, de facto, o nível de accountability exigido às 
estruturas empresariais, o que se repercutiu nos deveres dos auditores. Com efeito, Porter e Burton (1970, p. 610-615), Elliot (1995, p. 118-127), Sherer e Kent (1983, p. 3), Flint (1988, p. 19-20), além de referirem a fraude e a solvência das empresas, alargam o âmbito e o alcance da auditoria para o exame da informação financeira e não financeira, para o reporte do value for money das organizações e para a análise e monitorização do ambiente do controlo interno existente nas empresas. Os sistemas postulacionais de Sherer e Kent (1983) e de Flint (1988) nasceram neste enquadramento socioeconómico e num contexto de crescente criticismo da sociedade em relação à auditoria.

Delimitado o tema, no segundo capítulo faremos uma revisão da literatura existente. No terceiro exporemos a metodologia utilizada no trabalho. No quarto faremos uma análise comparativa evolutiva dos sistemas postulacionais propostos por Sherer e Kent (1983) e Flint (1988). No quinto capítulo discutiremos os resultados e, por fim, apresentaremos as conclusões, as limitações e sugestões para futuras investigações.

\section{REVISÃO DA BIBLIOGRAFIA}

Sherer e Kent (1983) e Flint (1988) são considerados, de uma maneira geral, os teoristas que, no Reino Unido, pretenderam dotar a auditoria, em sentido lato, de uma estrutura teórica consistente e de um alto nível explicativo para as práticas de auditoria existentes. Estes sistemas postulacionais representam uma tentativa de adaptação à auditoria, dos quadros concetuais britânicos $(1975,1995)$ que tiveram a sua origem no Corporate Report (1975). O primeiro reflete um contexto políticoeconómico dominado pelo período trabalhista, que determinava um papel para a contabilidade muito diferente do preconizado nos Estados Unidos. Neste país, o papel da contabilidade estava dirigido unicamente para os mercados financeiros, enquanto no U.K. a informação financeira é destinada também aos trabalhadores, analistas financeiros, clientes e público em geral: contribuintes, consumidores, partidos políticos, associações ecológicas, etc.

Tendo em conta todos estes stakeholders, a estrutura concetual previa a publicação, além das demonstrações financeiras tradicionais, de mapas de valor acrescentado, do balanço social, do quadro de relações financeiras com o Estado e de documentos previsionais. O contexto político e económico dessa época refletiu-se inevitavelmente no documento. Em 1995, a envolvente económica era diferente e os destinatários da informação financeira tendem a privilegiar os providers of risk capital, assumindo-se, assim, uma linha muito diferenciada relativamente ao Corporate Report (1975). A estrutura concetual de 1995 refletia a orientação do FASB (1985), do IASB (1989), bem como do Manual Canadiano (1988) no que concerne aos quadros concetuais da informação financeira destes países. Como salienta Pérez (1996:134), os sistemas postulacionais da auditoria financeira partilham as estruturas concetuais da contabilidade financeira: os seus objetivos estruturam-se ou fusionam-se à volta da imagem verdadeira e apropriada.

Os sistemas postulacionais dos autores inicialmente citados, Sherer e Kent $(1983$, p. 9) e Flint $(1988$, p. 7), consagraram a auditoria como uma variável endógena relativamente à sociedade, sendo o valor da auditoria julgado pela sua aptidão para promover e potenciar o processo de accountability das organizações, que deve ser direcionado para todos os stakeholders, fundamentando-se aquele numa necessidade social, envolvendo toda a associação produtiva interessada nas contas das empresas: auditores, organismos de auditoria e o conjunto dos grupos sociais (Flint, 1988, p. 12). A auditoria enquadrada num contexto sociopolítico é também referenciada por Tincker (1982, p. 58) e, neste espírito, a dimensão social atribuída pelos autores ingleses à auditoria confere-lhe um papel importante de mecanismo de controlo social: o processo de auditoria consiste em verificar o grau de cumprimento em relação a um conjunto de normas específicas que derivam do sistema social, abrangendo, por isso, matizes de caráter cultural, social e político. Os sistemas postulacionais 
ingleses para a auditoria financeira não são referenciados pela maioria dos autores ingleses de textos pedagógicos de auditoria.

\section{METODOLOGIA}

A metodologia utilizada é constituída por um conjunto de técnicas de procedimento que, pelo seu uso abrangente se erigiram em métodos, e que focam, em relação aos fenómenos observáveis, determinados domínios particulares. No caso concreto é utilizado, de forma concomitante, um mix de métodos: o histórico, o comparativo-tipológico, o monográfico e o interpretativo. Na realidade, na análise dos sistemas postulacionais, doravante SP, utilizámos o primeiro procedimento - método histórico - partindo do princípio de que aqueles têm a sua origem no passado, sendo, por isso, a pesquisa das suas raízes importante para compreender a sua natureza e função. Através desta metodologia investigámos os SP concebidos no passado com o objetivo de verificar a sua influência atual, tendo em conta o contexto particular de cada época e as suas modificações posteriores (Lakatos, 1981, p. 32; Ryan et al., 2001, p. 7-94).

Considerámos, ainda, as semelhanças e diferenças entre os diversos tipos de SP e, para isso, efetuámos comparações com a finalidade de examinar similitudes, explicar divergências e criar tipologias. Esta abordagem permite-nos analisar os SP, deduzir os elementos constantes, abstratos e gerais, e, por isso, o modelo comparativo foi utilizado, em todos os níveis, com o intuito de averiguar a analogia entre as diferentes estruturas. Permite-nos ainda classificar genericamente os SP e construir as respetivas representações, bem como as suas características típicas (Lakatos, 1981, p. 33; Weber, 1971).

O método monográfico foi também utilizado no estudo analítico dos SP com a finalidade de obter generalizações. Examinámos, assim, os seus aspetos particulares, respeitando a totalidade solidária dos seus criadores e seguidores.

Por fim, utilizámos o método funcionalista, estruturalista ou interpretativo, que é considerado mais um método de interpretação do que de investigação (Malinowski, 1978).

Sendo o nosso objetivo relacionar a emergência dos SP com a envolvente económica, bem como com o processo de desenvolvimento do capitalismo, que, em última análise, ditam a conceção dos postulados pelos diferentes autores, interpretámos os postulados de Mautz e Sharaf numa envolvente de evolução do capitalismo industrial, enquanto os postulados de Sherer e Kent, Flint e Lee são contextualizados numa envolvente de competitividade em contexto de incerteza, em que emerge o primado do consumo e do marketing, e se assiste à secundarização do primado da produção que envolveu a conceção dos SP de Mautz e Sharaf. Da comparação efetuada resultaram algumas quantificações que conferem ao estudo uma base empírico-qualitativa, ainda que minimalista e formulámos as seguintes hipóteses, que consideramos centrais à explicação da auditoria e do seu processo:

H1. Os sistemas postulacionais propostos por Sherer e Kent (1983) e Flint (1988) mantêm uma filosofia de auditoria idêntica, abarcando, no seu âmbito, um conceito mais amplo do que a abordagem meramente financeira?

H2. A função do auditor, na sociedade inglesa, estabilizou durante os anos 80 ?

H3. O número de postulados para justificar a realidade da auditoria é o mesmo em ambos os autores?

H4. A existência de auditoria interna pode dispensar a auditoria externa? 


\section{ANÁLISE COMPARATIVA DOS SISTEMAS POSTULACIONAIS}

Para responder a este conjunto de hipóteses relacionadas com os objetivos e a procura da auditoria, comportamento dos agentes e processo de auditoria, utilizámos o método comparativo, definindo previamente o conteúdo dos postulados justificativos, comportamentais e funcionais, através da definição de um conjunto de elementos constitutivos que dão corpo a cada uma das categorias de postulados, conforme o quadro seguinte.

Figura 1 - Postulados Básicos da Auditoria.

\begin{tabular}{|c|c|c|c|c|c|}
\hline \multicolumn{6}{|c|}{ Postulados básicos da auditoria } \\
\hline & & & & & \\
\hline & $\downarrow$ & & $\downarrow$ & & $\downarrow$ \\
\hline \multicolumn{2}{|r|}{$\frac{\downarrow}{\text { Justificativos }}$} & \multicolumn{2}{|c|}{ Comportamentais } & \multicolumn{2}{|r|}{ Funcionais } \\
\hline & & & & & \\
\hline \multirow{3}{*}{$\rightarrow$} & & & & & \\
\hline & Credibilidade & \multirow{2}{*}{$\rightarrow$} & Relações entre os agentes & \multirow{2}{*}{$\rightarrow$} & Referencial Contabilistico: \\
\hline & & & & & Comprovação/padrão \\
\hline \multirow[t]{2}{*}{$\rightarrow$} & Accountability & \multirow[t]{2}{*}{$\rightarrow$} & Imposições Legislativas & & \\
\hline & & & & $\rightarrow$ & Custo- Benefício \\
\hline \multirow[t]{2}{*}{$\rightarrow$} & Afastamento/Complexidade & \multirow{2}{*}{$\rightarrow$} & Formação/Competência & & \\
\hline & & & & $\rightarrow$ & Controlo Interno \\
\hline \multirow[t]{2}{*}{$\rightarrow$} & Teoria da agência & \multirow[t]{2}{*}{$\rightarrow$} & Independência & & \\
\hline & & & & $\mapsto$ & Ética \\
\hline \multirow[t]{3}{*}{$\longrightarrow$} & Lei & \multirow[t]{2}{*}{$\rightarrow$} & Parecer do auditor & & \\
\hline & & & & $\longrightarrow$ & Extrapolação \\
\hline & & & & & \\
\hline
\end{tabular}

Assim, os postulados justificativos são densificados observando os seguintes elementos ou atributos: credibilidade, accountability, afastamento/ complexidade, teoria da agência e lei. Este conjunto de elementos na totalidade ou de forma fragmentada, explícita ou implicitamente, é referido por Louwers et al. (2013, p. 1-32), Lee (1996, p. 93-100); Messier, Glover e Prawitt (2012, p. 3-23), Arens, Elder e Beasley (2010, p. 3-14), Whittington e Pany (2010, p. 1-31), Pérez (1996, p. 56-57), Molina e Pérez (1996, p. 2-25).

Os conteúdos que dão corpo aos aspetos comportamentais dos preparadores da informação financeira, gestores e auditores, materializam-se essencialmente na existência ou não de conflitualidade entre os agentes, nos códigos de ética e outras medidas de enforcement que condicionam o comportamento de todos dos agentes inseridos neste espaço profissional, na independência do auditor, na ética do seu comportamento e nos reflexos de todas estas vertentes no relatório de auditoria. Esta problemática é referida, entre outros, por Sherer e Kent (1983, p. 9), Lee (1996, p. 93), Flint (1988, p. 7), Almeida (2005, p. 39-50), Knechel (2001, p. 1-7), Messier, Glover e Prawitt (2012, p. 57-60), Whittington e Pany (2010, p. 63-103).

Por sua vez, os postulados funcionais que orientam o processo de auditoria e constituem um guia para enquadrar a ação, são preenchidos com a problemática do referencial contabilístico ou qualquer outro padrão de medida que possibilite a comprovação e a imputação de responsabilidades, baseadas em evidências verificáveis e submetidas ao padrão económico de custo/benefício. Integram ainda esta categoria de postulados, o ambiente do controlo e a extrapolação dos resultados. Todos estes elementos são referidos pelos teoristas de auditoria, entre os quais salientamos: Louwers et al. (2013, p. 168-210), Porter e Gowthorpe (2004, p. 363-406), Arens, Elder e Beasley (2010, p. 289-332), Messier, Glover e Prawitt (2012, p. 183-223).

Procedemos ainda à análise dos estudos existentes na literatura internacional, tanto na vertente normativo-descritiva, como na perspetiva empírica. 
Para Sherer e Kent, a auditoria fundamenta-se na teoria da agência, a qual tem subjacente uma relação de accountability entre os agentes, os principais e outros interessados nas entidades, ainda que não proprietários: stakeholder theory. Nesta teoria, aos managers são confiados recursos económicos e financeiros para gerirem em benefício dos proprietários, sendo, por isso, responsáveis perante eles. A relação de accountability transcende, porém, a ótica meramente financeira, alargando-se a todo um conjunto de entidades que contribuem para tornar a organização viável: bancos, empregados, consumidores, Estado, etc. Para todos eles deve ser facultada informação financeira e não financeira. Consideram, ainda, a auditoria como um mecanismo importante no processo de prestação de contas, por possibilitar, a toda a envolvente interessada na empresa, a monitorização da performance da organização e do comportamento dos managers.

A separação de funções de propriedade e de gestão das empresas, profundamente analisada por Berle e Means (1932) no processo de desenvolvimento empresarial nos Estados Unidos, implicou não só a transferência de poder para um número restrito de organizações, como acentuou a possibilidade da existência de conflitos entre os objetivos dos gestores da empresa e dos detentores do capital. Na ausência de conflitualidade, a função de auditoria externa limita-se a deteção de erros, omissões ou existência de fraude. Admitindo-se que os interesses são conflituantes e egoístas, o objetivo da auditoria, como mecanismo de accountability, visa limitar o comportamento oportuníssimo dos agentes.

Jensen e Meckling (1976) abordam a auditoria de forma análoga, mas distinguem a empresa em termos legais - inominali legal artefact - e a organização real - real entity - realçando a abstração da estrutura legal da empresa no processo de accountability. Com efeito, se tanto os agentes como os principais pretendem maximizar a sua utilidade, ocorrem, inevitavelmente, conflitos inerentes à gestão dos ativos e à repartição dos cash-flow: a empresa torna-se, assim, num nó de contratos. Os proprietários incorrem em custos de monitorização para controlar os agentes. Estes, por sua vez, reduzem os seus interesses oportunísticos até ao ponto em que ocorra um break-even point calculado com base nos chamados custos de litigação. Neste sentido, a apresentação e a divulgação da informação financeira, preparada pelos gestores e a sua validação por um auditor independente, é facultada aos proprietários pelos gestores em ordem a estes minimizarem os custos atrás citados: a teoria da agência, segundo Sherer e Kent $(1983$, p. 3), justifica a existência da auditoria estatutária na sociedade.

Adicionalmente, uma visão mais lata da organização empresarial reconhece que, para além dos proprietários, existe todo um conjunto de outros participantes com quem a organização tem relações económicas e sociais, situação que Rahman e McCosh (1976) sintetizou através do conceito de associação produtiva, e, neste contexto, todas as organizações podem ser encaradas como principais no processo da relação de accountability. Esta visão consagra uma extensão da teoria da agência por originar diferentes tipos de accountability na organização. Assim, a auditoria, dentro do processo de accountability, não se deve limitar unicamente à compliance audit, mas alargar o seu âmbito à análise da gestão eficiente, eficaz e económica dos recursos. Neste enquadramento, a auditoria financeira limita-se à contabilidade financeira, abrangendo a auditoria interna a gestão eficiente dos recursos da organização, abarcando a informação financeira e não financeira. $O$ valor da auditoria, segundo Sherer e Kent $(1983$, p. 9), só pode ser julgado pela sua aptidão para promover o processo de accountability das organizações, direcionada para todos os seus participantes. Reconhece, contudo, que este processo, sendo por natureza contingente, deve ter em consideração as características de cada organização e os objetivos dos seus stakeholders: a auditoria, como ciência sinótica, é considerada o mecanismo fundamental para promover e monitorizar o processo de accountability. 
Para estes autores, o objetivo fundamental da auditoria estatutária é essencialmente de natureza qualitativa, isto é, serve para reforçar a credibilidade das demonstrações financeiras apresentadas pelos gestores aos proprietários das empresas, além de ser imposta pela lei. Nesta sequência, é possível desenhar um conjunto de postulados e assunções que justifiquem a sua existência na sociedade, catalogados em postulados justificativos, comportamentais e funcionais. Enunciaremos os primeiros:

\section{Quadro 1 - Postulados Justificativos}

PJ1. Ao produto contabilístico - demonstrações financeiras - preparado pelos gestores e quadros de uma empresa ou organização é atribuído, genericamente, uma insuficiente credibilidade para merecer a confiança dos acionistas.

PJ2. Os legisladores acreditam que o reforço da credibilidade é o mais importante requisito de uma auditoria estatutária.

PJ3. É geralmente aceite que a auditoria estatutária faculta os melhores meios por reforçar a credibilidade das contas.

PJ4. Acredita-se que a credibilidade das contas pode ser reforçada ou verificada pela auditoria estatutária.

PJ5. Os acionistas estão impossibilitados de monitorizar pessoalmente a credibilidade da informação financeira das contas apresentadas pela empresa.

Estes cinco postulados justificativos da auditoria evidenciam que são da responsabilidade da administração da empresa a preparação, a apresentação e a divulgação da informação financeira produzida pelas empresas, que evidencie a origem e aplicações dos fundos, os capitais próprios, os resultados obtidos e a situação financeira. A conflitualidade na consecução destes objetivos é fundamentada na teoria da agência. Por sua vez, a potencial existência de muitos e variados enviesamentos limita a credibilidade da informação financeira não auditada. Por outro lado, os códigos comerciais dos diferentes países europeus (Portugal, Espanha, etc.) e as próprias diretivas comunitárias (quarta) requerem que os auditores exprimam a sua opinião relativamente ao conceito incontornável do true and far view, que é, por natureza, um conceito global, e relegam para segundo plano outras alternativas possíveis: validar, por exemplo, individualmente todos as linhas do balanço ou da demonstração de resultados. Por outro lado ainda, a lei não apresenta nenhuma outra opção para validação das contas das empresas, situação que indicia uma assunção aceitável por todos.

Tendo em conta o conceito amplo de auditoria de Sherer e Kent (1983), a lei poderia ter consignado, por exemplo, que as empresas dotadas de um departamento de auditoria interna, responsável pela validação da informação financeira e não financeira, e responsável também pela eficiência e eficácia e economicidade na alocação dos recursos patrimoniais, não fossem sujeitas obrigatoriamente a uma auditoria externa. Não o fez, porém. O quarto postulado tem subjacente a ideia de que a credibilidade pode ser reforçada ou verificada através de uma auditoria estatutária. No entanto, o auditor faculta somente uma opinião sobre as demonstrações financeiras e, neste espírito, nunca pode dar uma segurança absoluta, mas razoável, relativamente às contas apresentadas pela administração. A responsabilidade relaciona-se com o desenvolvimento do próprio processo de auditoria e com a tarefa de auditor que analisa as transações, não na sua universalidade, mas utilizando técnicas de amostragem. Por outro lado, a existência de um conjunto de estimativas e julgamentos efetuados pela administração e refletidos nas contas das empresas, impede o profissional de facultar uma garantia absoluta sobre as contas apresentadas e divulgadas. Assim, as partes interessadas na auditoria devem tomar conhecimento dos constrangimentos inerentes à função, para que não existam expetativas defraudadas da sociedade em relação ao trabalho dos auditores.

Neste contexto, o termo verificar é considerado problemático quando aplicado em auditoria financeira por criar a ilusão, nos utilizadores, de que os auditores analisam toda a informação disponível numa organização, o que, como vimos, não é verdade. Por fim, o quinto postulado refere 
que o afastamento dos acionistas relativamente às empresas, a complexidade e a dimensão das organizações empresariais, são situações impeditivas de qualquer acionista médio, isoladamente considerado, reunir as competências, tendencialmente suficientes, para auditar contas de uma empresa. Surge, deste modo, a necessidade da intervenção de uma terceira pessoa: o auditor independente.

Relativamente aos postulados comportamentais, Sherer e Kent (1983, p. 20-21) sugerem que a auditoria é um serviço intangível, cuja existência está estritamente relacionada com a qualidade percecionada pela sociedade, do comportamento dos auditores e dos gestores da empresa, e referem os seguintes postulados:

\section{Quadro 2 - Postulados Comportamentais}

PC 1. A auditoria não pode ser obstaculizada pela existência de conflitos entre o auditor e a empresa.

PC 2. A lei não restringe a atividade do auditor.

PC 3. O auditor é totalmente independente em termos mentais e físicos.

PC 4. O auditor é suficientemente competente no desenvolvimento da sua missão.

PC 5. O auditor é responsável pela qualidade do seu trabalho e pela emissão da sua opinião.

Este conjunto de assunções relaciona-se com a coluna vertebral da auditoria: independência, competência, integridade e responsabilidade. A auditoria não pode existir sem uma aceitação e perceção generalizadas, por parte do público, de que é planificada e conduzida por um corpo profissional independente da gestão das empresas e devotado ao serviço de todos os stakeholders.

Os auditores são objetivos e expressam uma opinião independente da entidade e dos respetivos gestores. Assim, a sua independência profissional é essencialmente um estado de espírito constituído por três componentes: (1) independência na planificação da auditoria: que consiste em liberdade total para desenvolver o desenho dos programas de auditoria mais adaptados à empresa e definir os limites de materialidade adequados, dentro do risco assumido para a auditoria; (2) independência de investigação: que se materializa no acesso a todas as fontes de informação disponíveis e legais existentes na empresa, o que significa a liberdade de não aceitar qualquer limitação à finalidade da auditoria; (3) independência quando emite a sua opinião: que se consubstancia na ausência de quaisquer tipos de compromisso relativamente à entidade auditada. A emissão do seu relatório não pode ser afetada por influências que comprometam o seu juízo profissional, a sua integridade, independência, objetividade e ceticismo profissional. Acresce que o processo de auditoria deve ser conduzido de uma forma profissional e competente, todavia, a independência é uma condição necessária mas não suficiente. Aquele atributo tem de estar ligado à competência e à integridade do auditor como referem Johnstone e Bedard (2001, p. 1-18) e Taylor (2003, p. 257-266), condição essencial e necessária para que o risco de informação, para todos os interessados se reduza.

Por fim, o auditor, ao emitir a sua opinião, defronta-se com a possibilidade de ser demandado judicialmente. Modernamente, refere-se a responsabilidade social do auditor, por ser considerada um conceito mais amplo do que a responsabilidade administrativa - não cumprimento do quadro jurídico-técnico que regulamenta a profissão - e do que a responsabilidade civil e penal - a imputar, ao auditor, pelos tribunais. Estas responsabilidades constituem aspetos parciais da responsabilidade social: esta significa a obrigação moral, adquirida no desenvolvimento da sua profissão de interesse público, que se identifica como o bem-estar coletivo das comunidades, das pessoas e das instituições que o auditor serve. A existência da responsabilidade social do auditor equivale a atribuir, à auditoria, uma função social.

Além dos postulados básicos ou justificativos e comportamentais, Sherer e Kent (1983, p. 22) apresentam mais três postulados funcionais relacionados com o trabalho desenvolvido pelo auditor: recolha de evidência, análise do controlo interno e observação dos princípios contabilísticos geralmente aceites. Assim: 
Quadro 3-Postulados Funcionais

PF 1. Assume-se que a existência de evidências suficientes e fiáveis e em forma apropriada, possibilitam, ao auditor, conduzir uma auditoria em tempo e custos razoáveis (custo-benefício).

PF 2. Admite-se que a existência de um bom sistema de controlo interno afasta, à partida, a possibilidade da existência de fraudes e erros relevantes.

PF 3. Aceita-se que o cumprimento das bases conceptuais subjacentes à informação financeira, os princípios e as normas de contabilidade geralmente aceites, de uma forma apropriada e consistente, conduzem à apresentação verdadeira e apropriada das contas da empresa.

A auditoria é concebida pelo American Accounting Association (1973) como um processo sistemático de obter e avaliar objetivamente evidências relativamente às afirmações relacionadas com atos e acontecimentos económicos, a fim de avaliar tais declarações à luz dos critérios estabelecidos e comunicar o resultado às partes interessadas. $O$ primeiro postulado funcional refere-se naturalmente à teoria da evidência como um conjunto de proposições integrantes do processo de auditoria, que, relacionadas de forma ordenada e lógica, justificam o teor da opinião emitida.

Esta axiomática compreende o desenho do programa de auditoria e a avaliação da evidência, sendo assumida por Mautz e Sharaf $(1961$, p. 94) como a principal tarefa do auditor e, neste sentido, a evidência deve ter qualidade e ser suficiente, não para o auditor chegar a uma certeza absoluta, como se verifica nas ciências quantitativas, mas para obter uma certeza razoável, baseada na plena confiança e conviç̧ão de que a emissão do parecer não é arriscada. Trata-se de um grau de segurança ditado pela prudência, que é utilizado na maior parte das atividades humanas, a que se chama certeza moral. A quantidade de evidência, de acordo com o postulado em análise, deve obedecer ao binómio custo-benefício e ser tempestiva: por isso, deve ser submetida a uma avaliação do custo que pressupõe a obtenção de mais evidência e, de seguida, relacioná-lo com o proveito final dos resultados que se espera obter. Acresce que a obtenção de evidência deve ainda ter em conta duas âncoras fundamentais do processo de auditoria: a materialidade e o risco de auditoria (Perez et al., 2012, p. 57).

O segundo postulado tem subjacente uma avaliação crítica do sistema de contabilidade e do controlo interno. Atualmente as normas de auditoria, bem como algumas instituições reguladoras (PCAOB, 2006), exigem que o auditor estude e avalie o sistema de controlo interno, os sistemas de contabilidade, os controlos administrativos e os controlos contabilísticos internos: todos eles devem permitir, a este profissional, compreender o ambiente de controlo interno existente na empresa e o subjacente processamento das operações através da contabilidade. Esta avaliação preliminar permite identificar as principais deficiências visíveis do controlo interno.

O controlo interno contabilístico deve estar orientado para a proteção dos ativos e dos recursos da empresa, para fomentar a fiabilidade do sistema de informação da empresa, devendo integrar, para atingir esse fim, um conjunto de técnicas que permitam a satisfação dos seus objetivos gerais: autorizações apropriadas, correta classificação contabilística, verificação e avaliação e salvaguarda física dos ativos. Como objeto operativo, o controlo interno deve considerar ainda os seguintes aspetos: reconhecimento das transações, acontecimentos e factos económicos, aceitação das transações, integridade de processamento, integridade dos relatórios, base de dados e integridade das conexões. Estes objetivos gerais e operativos, que têm subjacente a ideia de integridade, realidade e exatidão, relacionam-se estritamente com os objetivos da auditoria: integridade, existência e integralidade. Este postulado é de grande importância para a auditoria, por existir uma impossibilidade física e técnica de identificação de todas as transações, e, neste contexto, a existência de um sistema de controlo interno de bom nível garante, em princípio, que as contas preparadas, apresentadas e divulgadas estejam razoavelmente isentas de fraudes e de erros relevantes. 
Admite-se, por fim, de acordo com o terceiro postulado, que as estruturas conceptuais da contabilidade, os princípios e normas contabilísticas, quando observados com rigor e consistência, proporcionam uma imagem verdadeira e apropriada dos ativos, dos passivos, dos capitais próprios e dos resultados e a posição financeira da entidade auditada. Como as operações contabilísticas ganharam cada vez mais complexidade e requerem, por isso, um maior tecnicismo, a auditoria foi sendo dominada progressivamente pelo corpo profissional dos contabilistas: reside, aqui, a génese de muitos problemas que se debatem, na atualidade, no campo da auditoria. Esta base contabilística da auditoria é uma fonte de diferenças de expetativas. De facto, a contabilidade está baseada numa ótica utilitarista ou de conveniência caracterizada pela constante subordinação ao pragmatismo dos princípios morais e éticos.

As demonstrações financeiras têm subjacente uma imensa teia de convenções contabilísticas, de dados históricos, de fatos presentes, de estimativas, riscos e incertezas, que os próprios contabilistas têm dificuldade em filtrar, na hora de distinguir a verdade da fiç̧ão. No entanto, a estrutura básica de princípios e normas, ainda que contingente, constitui uma base otimizada para responder às características qualitativas da informação financeira: relevância, comparabilidade, consistência e prudência. Neste contexto, a validação do ideal de auditoria - imagem verdadeira e apropriada ainda que produzida na observância de normas reconhecidas, permite uma grande base de julgamento na interpretação dos princípios e normas, bem como da sua aplicação prática. De facto, os princípios e normas nunca foram contrastados empiricamente, nem, tão pouco, foram cientificamente verificados, e, por sua vez, a sua legitimidade deriva da sua aceitação geral. Como consequência o auditor, para cada asserção, análise ou valorização, efetua, no desenvolvimento do próprio processo de auditoria, diversas reflexões ou juízos, a saber: julga a competência da gestão, analisa a eficácia e a arquitetura do sistema de informação, calcula a materialidade e determina o risco de auditoria. A investigação, nesta área, é imprescindível e deve ser guiada por um pensamento crítico permanente.

O método monográfico permite-nos considerar o sistema postulacional de Sherer e Kent (1983), realçando as seguintes características:

Quadro 4 - Síntese do sistema postulacional de Sherer e Kent (1983)

\begin{tabular}{|c|c|c|c|}
\hline & Aspetos a considerar & Caraterização & Notação \\
\hline 1 & Envolvente dos negócios & $\begin{array}{l}\text { Envolvente mais incerta, maior } \\
\text { imprevisibilidade, extrapolação mais difícil. }\end{array}$ & SK1 \\
\hline 2 & Âmbito da auditoria & $\begin{array}{l}\text { Abordagem financeira e não financeira: a } \\
\text { auditoria não deve limitar-se à compliance } \\
\text { audit, mas abarcar outros aspetos relacionados } \\
\text { com a gestão económica, eficaz e eficiente dos } \\
\text { recursos. }\end{array}$ & SK2 \\
\hline 3 & Conceção de auditoria & $\begin{array}{l}\text { Social: limitar o comportamento oportunístico } \\
\text { dos agentes. }\end{array}$ & SK3 \\
\hline 4 & Interesse na auditoria & Interesse público: stakeholders. & SK4 \\
\hline 5 & Informação como bem económico & Bem público. & SK5 \\
\hline 6 & Responsabilidade do auditor & Social. & SK6 \\
\hline 7 & Forma vs. Substância & Substância em detrimento da forma. & SK7 \\
\hline 8 & Relações entre agentes & $\begin{array}{l}\text { Existência de conflitualidade entre os agentes e } \\
\text { os principais. }\end{array}$ & SK8 \\
\hline 9 & Continuidade da empresa & $\begin{array}{l}\text { Em todas as circunstâncias e não só por } \\
\text { exceção. }\end{array}$ & SK9 \\
\hline 10 & Deteção de erros, omissões e fraudes & $\begin{array}{l}\text { Como a auditoria tem uma função social, a } \\
\text { sociedade impõe-se à auditoria, e esta função } \\
\text { está implícita no conceito. }\end{array}$ & SK10 \\
\hline
\end{tabular}




\begin{tabular}{|c|l|l|c|}
\hline 11 & $\begin{array}{l}\text { Caraterística mais relevante da } \\
\text { informação financeira }\end{array}$ & Relevância. & SK11 \\
\hline 12 & Risco de auditoria. & Risco Empresarial/do negócio/ou estratégico. & SK12 \\
\hline 13 & True and fair view & $\begin{array}{l}\text { Cumprimento das bases concetuais da } \\
\text { informação financeira conduz a "este objetivo". }\end{array}$ & SK13 \\
\hline 14 & Linearidade vs. Incerteza & $\begin{array}{l}\text { A linearidade/extrapolação, tendo em conta a } \\
\text { envolvente dos negócios, é de mais difícil } \\
\text { concretização. }\end{array}$ & SK14 \\
\hline 15 & Responsabilidades da auditoria & $\begin{array}{l}\text { Mais amplas do que as meramente técnicas, a } \\
\text { responsabilidade é social. }\end{array}$ & SK15 \\
\hline 16 & $\begin{array}{l}\text { Independência, estatuto profissional e } \\
\text { condução ética }\end{array}$ & $\begin{array}{l}\text { Fundamental para desenvolver o processo de } \\
\text { auditoria. Sem independência a auditoria não } \\
\text { existe. }\end{array}$ & SK16 \\
\hline 17 & $\begin{array}{l}\text { Necessidade de recurso a auditoria } \\
\text { interna }\end{array}$ & $\begin{array}{l}\text { Admite-se que as empresas dotadas de um } \\
\text { departamento de auditoria interna sejam } \\
\text { dispensadas de auditor externo. }\end{array}$ & SK17 \\
\hline
\end{tabular}

A abordagem da auditoria proposta pelo inglês Flint é de uma grande abrangência. Este autor defende que toda a construção teórica da auditoria deve ser baseada no seguinte pensamento:

O conceito social de auditoria compreende um exame realizado por uma determinada pessoa, independente das partes envolvidas, que compara o produto final com os objetivos e comunica os resultados obtidos: é, portanto, uma parte essencial do sistema de mecanismo de controlo público e privado.

Esta conceção constitui a base da construção da teoria e dos processos e normativos da auditoria, sendo bastante mais ampla do que a proposta de Mautz e Sharaf (1961) e Sherer e Kent (1988), por permitir abarcar as atividades não financeiras e, inclusivamente, atividades sem processamento contabilístico. Flint (1988) estrutura e desenvolve o seu conceito de auditoria, formulando um número básico de postulados sobre os quais a teoria repousa, permitindo, desta forma, 0 desenvolvimento de princípios que permitam alicerçar a sua prática. A sua teoria permite a interação com a sociedade ao afirmar que é o negócio ou ética pública (Flint, 1988, p. 7) que a auditoria procura, em última instância, monitorizar e validar. Neste contexto, o conceito social de auditoria é adaptativo e a sua interpretação operacional depende não só dos valores éticos, mas também do valor de julgamento efetuado pela sociedade em relação aos aspetos a que a prestação de contas deve ser aplicada.

A função de auditoria deve abarcar informação para além da prestada pela contabilidade, envolvendo aspetos relacionados com o value for money, ou seja, a economia, a eficiência e a eficácia da gestão das organizações. É, assim, considerada, à semelhança de Sherer e Kent (1973), como um mecanismo de controlo, por verificar a conduta e a performance das organizações (Flint, 1988, p. 12). Deste modo, a auditoria fundamenta-se numa necessidade social, envolvendo uma interação entre os auditores, os organismos de auditoria e o conjunto de grupos sociais.

Mautz e Sharaf (1961, p. 2) afirmaram que a função que o auditor atribui a si próprio pode ser aceite ou rejeitada pela sociedade. Assim, ou o grupo encontra um papel aceite pela sociedade ou desaparece. A sociedade, em constante mudança, pode não aceitar papéis formalmente aceitáveis, e, neste sentido, os grupos profissionais devem estar em constante alerta e recetivos à modificação e à revisão do seu papel. Tincker $(1982$, p. 58) argumenta que a auditoria tem de ser enquadrada num contexto sociopolítico e num modelo de regulação empresarial em que o dever de prestação de contas é a sua característica fundamental. 
O enquadramento da auditoria num contexto social, e a sua procura, cada vez mais intensa, face à exiguidade de recursos nas organizações públicas e privadas, são situações que conferem à função um papel importante de mecanismo de controlo da sociedade. Neste contexto, o processo de auditoria consiste em verificar o grau de cumprimento em relação a um conjunto de normas específicas que derivam do sistema social, abrangendo, por isso, matizes de carácter cultural, social e político.

A auditoria, na conceção de Flint $(1988$, p. 13), tem uma clara dependência cultural. O conceito pode permanecer constante no tempo, enquanto a prática da função pode e deve adaptar-se aos valores da sociedade, às suas exigências e necessidades atuais. Aqueles, estando em contínua mutação, necessitam, por parte dos auditores, de respostas adequadas para os problemas emergentes de novas conceções e valores sociais.

Auditoria e interesse público são duas faces da mesma moeda: os auditores devem expressamente reconhecer não só o seu cliente como interessado no seu trabalho, mas também, todo um conjunto de entidades que nele confiam, situação que lhe confere um interesse público manifesto.

Nesta conceção abrangente da auditoria, Flint (1988, p. 19-41) concebeu um conjunto de postulados e de princípios gerais, sobre os quais repousa o seu sistema postulacional. Os postulados propostos, sendo o alicerce do desenvolvimento da teoria da auditoria, descrevem também as suas caraterísticas intrínsecas e constituem um padrão de comparação para os potenciais problemas de auditoria que se coloquem na sua aplicação e desenvolvimento prático. $O$ sistema postulacional de Flint, à semelhança do apresentado por Mautz e Sharaf, não cataloga os postulados, mas enfatiza o facto gerador da auditoria e os seus efeitos derivados. Vejamos:

Figura 2 - Estrutura conceptual de Flint

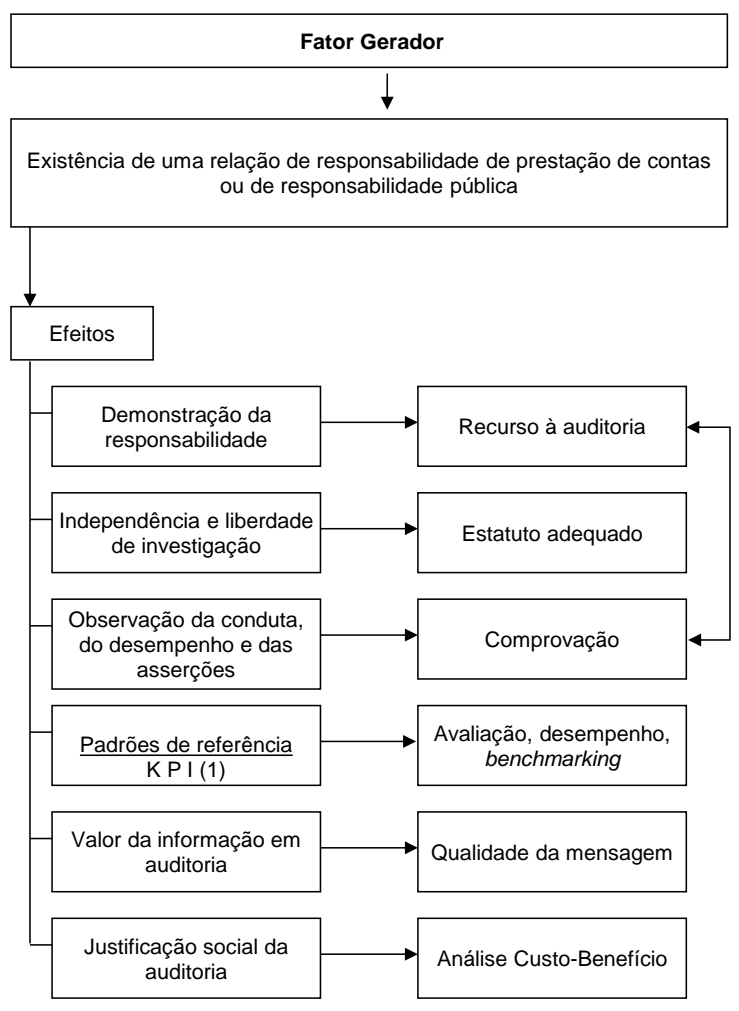

(1) KPI - Key Performance Indicators 
O fator gerador da auditoria define a sua essência, que está assente na existência de uma relação de responsabilidade, de prestação de contas ou de responsabilidade pública. A auditoria existe porque há necessidade de provar a validade das informações financeiras produzidas por quem tem o dever de prestação de contas, sendo seu o desempenho avaliado em função de um critério estabelecido a priori.

A qualidade da informação é importante para os utilizadores. Todavia, o seu valor é limitado até ao momento de ser submetida a uma verificação independente que ateste a excelência da informação financeira ou não financeira. Como corolário, a fiabilidade e a credibilidade da informação prestada, por uma das partes envolvidas numa relação de responsabilidade pela prestação de contas, explica a condição primária para a existência de uma auditoria. Este fator gerador sugere uma justificação da auditoria baseada na teoria da agência. Esta situação insere-se no mecanismo de atribuição de responsabilidades, que o conceito social de auditoria necessariamente incorpora.

Os efeitos derivados decorrem da adoção, e de acordo com o conceito amplo de auditoria proposto, de quatro referenciais básicos: verificação e comprovação, responsabilidade, independência e ética e económico.

a) Referencial de verificação e comprovação: a este referencial está ligado um postulado justificativo e outro funcional:

- As questões centrais relativas à responsabilidade apresentam-se muito dispersas, são complexas, e/ou de grande importância para o cumprimento/desempenho de obrigações/deveres; assim, para poderem ser demonstradas são submetidas ao processo de auditoria;

- As questões centrais relativas aos elementos da auditoria (conduta, desempenho, realização, registo dos acontecimentos, asserções, verificação de factos, etc.) têm de ser comprovadas por evidências.

Como a auditoria é uma investigação ou uma procura de evidências que permite a formulação de uma opinião sobre a imagem verdadeira e apropriada das demonstrações financeiras ou outro tipo de informação, apoia-se nos postulados supra descritos.

b) Referencial de responsabilidade: no processo de atribuição de responsabilidades é necessário recorrer a um método de investigação, mais ou menos desenvolvido, mais ou menos complexo consoante a empresa em causa, que não pode ser acionado sem o exame do auditor. Neste referencial existe um evidente conceito de relatividade, porque é a maior ou menor complexidade da organização que impõe a atribuição de responsabilidades (accountability), que pode ser adequadamente outorgada em demonstrações financeiras não auditadas. No entanto, o fundamento do referencial radica prioritariamente nas organizações mais complexas, em que o afastamento, a complexidade do negócio e da organização e a materialidade dos valores envolvidos, formam um quadro que evidência que o processo de auditoria é necessário e fundamental no processo de atribuição de responsabilidades, na verificação do desempenho e na análise da informação prestada. Deste modo, se a auditoria faz parte do processo de controlo social (Flint, 1988, p. 28) cuja característica básica é a atribuição de responsabilidade, esta não existe sem a captação de evidências que suportem a opinião do auditor.

É neste quadro de procura de evidências do sistema contabilístico, no modelo de controlo interno e na execução de procedimentos analíticos, que se estrutura e desenvolve um conjunto de normas de auditoria cuja aplicação potencia o aparecimento de opiniões divergentes entre os auditores e os utilizadores da informação financeira. 
c) Referencial de independência e de ética: o desenvolvimento do processo de auditoria, bem como a procura das evidências, envolve investigação, exame, avaliação da conduta, grau do cumprimento dos objetivos e das asserções do órgão de gestão. Este quadro coloca, como traves mestras da auditoria, a independência em relação à organização auditada e a ética do auditor. Se o objetivo básico de auditoria é a atribuição de responsabilidades, a sua materialização exige a emissão de uma opinião independente da entidade e dos diretores. Estamos em presença de um postulado que define um referencial de responsabilidade e de ética no desenvolvimento de uma auditoria, redigido por Flint (1988:29) da seguinte forma: "as características básicas distintivas fundamentais para o desenvolvimento de uma auditoria são a independência do estatuto do auditor e a sua liberdade relativamente às limitações de investigação e de emissão de parecer. Esta narrativa incorpora três postulados comportamentais".

A independência resulta obviamente da autoridade do auditor centrada num núcleo multidisciplinar de conhecimentos de alto nível: domínio pericial de todos os instrumentos de auditoria, conceção do seu papel no controlo social das organizações e aceitação social da sua função. A competência e a autoridade são indispensáveis para realizar o conceito de auditoria proposto por Flint, sendo a independência o núcleo central sem o qual, obviamente, a auditoria é posta em causa.

Desenvolvido o processo de auditoria e obtidas as evidências num quadro de independência profissional, o auditor está em condições de avaliar o desempenho da organização e o grau de cumprimento das asserções do órgão de gestão. Pressupõe-se, neste quadro, que os responsáveis pela organização, tendo a responsabilidade da prestação de contas, conhecem os padrões de referência. Neste contexto, em termos de aceitação contratual pelas partes envolvidas, se não for possível especificar o padrão de conduta, de desempenho ou da qualidade de informação pretendida, não estão preenchidos os requisitos básicos para desenvolver o processo de auditoria.

Sendo a auditoria um conceito de entendimento universal, a sua interpretação operacional está, contudo, relacionada com o tipo específico de responsabilidade que se pretende auditar (Flint, 1988, p. 33), em cujo âmbito podemos englobar as seguintes componentes: a honestidade, a regularidade, a legalidade, a lucratividade, a economia, a eficiência e a eficácia, ou qualquer outro critério de referência aceitável. A dificuldade de fixação de critérios é notória. Com efeito, os conceitos de honestidade, verdade e integridade radicam na cultura da sociedade e das organizações. Deste modo, os padrões de conduta dos auditores e de toda a normativa que lhes dá suporte podem conflituar com aquilo que a sociedade espera daqueles profissionais. Assim, normas deficientes ou a sua não observância podem gerar expectativas diferentes aos utilizadores. A mensagem básica deste postulado é que os KPI têm de ser aferidos às organizações. Sendo a auditoria financeira a validação do referencial contabilístico, esta situação potencia o desenvolvimento de expectativas sociais que os auditores, no quadro jurídico-técnico do exercício da profissão, não querem, ainda, aceitar.

d) O referencial económico incorpora três postulados funcionais - um relacionado com o valor da informação: o significado e a intenção das demonstrações financeiras e outras, bem como os dados que são auditados, são suficientemente claros para que a credibilidade que lhes é atribuída, como resultado da auditoria, seja claramente expressa e transmitida. O segundo, como justificação social para a sua existência, submete a auditoria à lógica do custo/benefício e o terceiro refere-se aos padrões de responsabilidade.

Segundo o primeiro postulado, a auditoria produz um benefício económico e social, e fundamentase no valor acrescentado proporcionado ao valor da informação das demonstrações financeiras. Por isso, a opinião expressa pelo auditor confere credibilidade, significado e relevância às demonstrações financeiras. A mensagem do auditor tem que ser claramente expressa, sendo o seu relatório crucial no processo de auditoria (Flint, 1988, p. 38). 
O segundo analisa a auditoria comparando os custos incorridos com os proveitos obtidos. Deste modo, atendendo à sua função utilitária, a sua adoção, como mecanismo de controlo social, é aceite se o benefício que possa proporcionar for superior ao custo suportado. O benefício social da auditoria é frequentemente intangível (Flint, 1988, p. 39), e neste sentido o seu custo económico é mensurado de um modo subjetivo pela sociedade. Com efeito, o providing value - um dos princípios fundamentais da auditoria independente - significa que a auditoria proporciona aos diferentes utilizadores uma mensagem credível da fiabilidade das demonstrações financeiras, e que os auditores estão numa excelente posição para incrementar o value for money. Todavia, a justificação social da auditoria tem que ser sempre medida em termos de custo e tempo, como é referido por Mautz e Sharaf (1961, p. 85). O terceiro postulado, para que o desempenho e a conduta possam ser avaliadas, refere a necessidade da existência de padrões de referência. Da análise monográfica efetuada enfatizamos dezassete pontos relevantes, expressos no quadro seguinte:

Quadro 5 - Síntese do sistema postulacional de Flint (1988)

\begin{tabular}{|c|c|c|c|}
\hline & Pontos relevantes & Caracterização & Notação \\
\hline 1 & Envolvente dos negócios & $\begin{array}{l}\text { Envolvente mais estável, maior imprevisibilidade } \\
\text { e incerteza. }\end{array}$ & F1 \\
\hline 2 & Âmbito da auditoria & $\begin{array}{l}\text { Abordagem financeira e não financeira e } \\
\text { inclusivamente de atividades sem reflexo } \\
\text { contabilístico. }\end{array}$ & F2 \\
\hline 3 & Conceção de auditoria & Social: instrumento de controlo social. & F3 \\
\hline 4 & Interesse na auditoria & Interesse público: stakeholders. & F4 \\
\hline 5 & Informação como bem económico & Bem público. & F5 \\
\hline 6 & Responsabilidade de auditor & Social. & F6 \\
\hline 7 & Forma vs. Substância & Substância em detrimento da forma. & F7 \\
\hline 8 & Relações entre agentes & $\begin{array}{l}\text { Existência de conflitualidade entre os agentes e } \\
\text { os vários principais. }\end{array}$ & F8 \\
\hline 9 & Continuidade da empresa & Em todas as circunstâncias e não só por exceção. & F9 \\
\hline 10 & Deteção de erros, omissões e fraudes & $\begin{array}{l}\text { Esta tarefa do auditor está no alcance da } \\
\text { auditoria, por esta ter uma função social. }\end{array}$ & F10 \\
\hline 11 & $\begin{array}{l}\text { Caraterística mais relevante da informação } \\
\text { financeira }\end{array}$ & Relevância. & F11 \\
\hline 12 & Risco de auditoria & Risco: empresarial, de negócio ou estratégico. & F12 \\
\hline 13 & True and fair view & $\begin{array}{l}\text { Transcende o conceito de true and fair view, } \\
\text { admitindo a existência de outros padrões. }\end{array}$ & F13 \\
\hline 14 & Linearidade vs. Incerteza & $\begin{array}{l}\text { A linearidade e a extrapolação nesta abordagem } \\
\text { carecem de sentido, tendo em conta a } \\
\text { envolvente dos negócios. }\end{array}$ & F14 \\
\hline 15 & Responsabilidades da auditoria & $\begin{array}{l}\text { Mais amplas do que as meramente técnicas: a } \\
\text { responsabilidade da auditoria é social. }\end{array}$ & F15 \\
\hline 16 & $\begin{array}{l}\text { Independência, estatuto profissional, e } \\
\text { condução ética }\end{array}$ & $\begin{array}{l}\text { Fundamentais para desenvolver o processo de } \\
\text { auditoria: sem independência a auditoria nada } \\
\text { vale. }\end{array}$ & F16 \\
\hline 17 & $\begin{array}{l}\text { Necessidade de recurso a auditoria } \\
\text { externa. }\end{array}$ & A auditoria interna pode ser suficiente. & F17 \\
\hline
\end{tabular}

1. Resultados Obtidos

Obtivemos, tendo em atenção as metodologias propostas e as âncoras utilizadas para dar conteúdo aos postulados, os seguintes quadros comparativos: 


\begin{tabular}{|c|c|c|}
\hline \multicolumn{3}{|c|}{ Quadro 6-Postulados justificativos dos SP } \\
\hline & Sherer e Kent (1983) & Flint (1988) \\
\hline \multirow{4}{*}{$\begin{array}{l}\frac{0}{0} \\
\frac{\pi}{0} \\
\frac{.}{\overline{0}} \\
\frac{\overline{0}}{0} \\
\frac{d}{U}\end{array}$} & $\begin{array}{l}\text { - Ao produto contabilístico - demonstrações } \\
\text { financeiras - preparado pelos gestores e quadros de } \\
\text { uma empresa ou organização é atribuído, } \\
\text { genericamente, uma insuficiente credibilidade para } \\
\text { merecer a confiança dos acionistas. }\end{array}$ & \\
\hline & $\begin{array}{l}\text { - Os legisladores acreditam que o reforço da } \\
\text { credibilidade é o mais importante requisito de uma } \\
\text { auditoria estatutária. }\end{array}$ & \\
\hline & $\begin{array}{l}\text { - É geralmente aceite que a auditoria estatutária } \\
\text { faculta os melhores meios por reforçar a } \\
\text { credibilidade das contas }\end{array}$ & \\
\hline & $\begin{array}{l}\text { - Acredita-se que a credibilidade das contas pode } \\
\text { ser reforçada ou verificada pela auditoria } \\
\text { estatutária. }\end{array}$ & \\
\hline 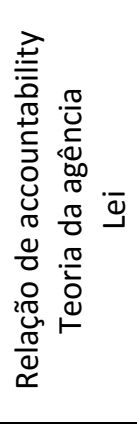 & & $\begin{array}{l}\text { - A condição essencial para uma auditoria é } \\
\text { que exista uma relação de responsabilidade ou } \\
\text { uma situação de responsabilidade pública. As } \\
\text { questões centrais relativas à responsabilidade } \\
\text { são longínquas, apresentam-se muito } \\
\text { dispersas, e/ou têm uma grande importância } \\
\text { para o cumprimento/desempenho de } \\
\text { obrigações/deveres. Consequentemente, para } \\
\text { que possam ser demonstradas tem que se } \\
\text { recorrer ao processo de auditoria. }\end{array}$ \\
\hline 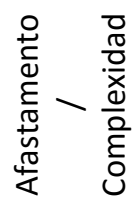 & $\begin{array}{l}\text { - Os acionistas estão impossibilitados de } \\
\text { asseverarem pessoalmente a credibilidade da } \\
\text { informação financeira das contas apresentadas pela } \\
\text { empresa. }\end{array}$ & \\
\hline
\end{tabular}

Quadro IX - Postulados comportamentais dos SP.

\begin{tabular}{|c|c|c|}
\hline & Sherer e Kent (1983) & Flint (1988) \\
\hline 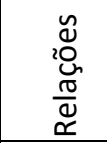 & $\begin{array}{l}\text { - A auditoria não pode ser obstaculizada pela } \\
\text { existência de conflitos entre o auditor e a empresa. }\end{array}$ & - \\
\hline 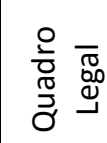 & - A lei não restringe a atividade do auditor. & \\
\hline 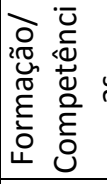 & $\begin{array}{l}\text { - O auditor é suficientemente competente no } \\
\text { desenvolvimento da sua missão. }\end{array}$ & $\begin{array}{l}\text { - O processo de avaliação e comprovação exige não } \\
\text { só uma aptidão especial, como também o exercício } \\
\text { de julgamento. }\end{array}$ \\
\hline 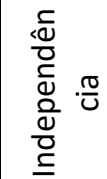 & $\begin{array}{l}\text { - O auditor é totalmente independente em termos } \\
\text { mentais e físicos. }\end{array}$ & $\begin{array}{l}\text { - As características distintivas fundamentais para } \\
\text { uma auditoria são a independência dos seus } \\
\text { estatutos e a sua liberdade relativamente à } \\
\text { investigação e ao relatório. }\end{array}$ \\
\hline
\end{tabular}




\begin{tabular}{|c|c|c|}
\hline & & $\begin{array}{l}\text { - O significado e a intenção das demonstrações } \\
\text { financeiras e outras, bem como os dados que são } \\
\text { auditados são suficientemente claros para que a } \\
\text { credibilidade que lhes é atribuída, como resultado } \\
\text { de uma auditoria, seja claramente expressa e } \\
\text { transmitida. }\end{array}$ \\
\hline 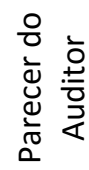 & $\begin{array}{l}\text { - O auditor é responsável pela qualidade do seu } \\
\text { trabalho e pela emissão da sua opinião. }\end{array}$ & \\
\hline
\end{tabular}

Quadro 7 - Postulados funcionais dos SP

\begin{tabular}{|c|c|c|}
\hline & Sherer e Kent (1983) & Flint (1988) \\
\hline \multirow{2}{*}{ 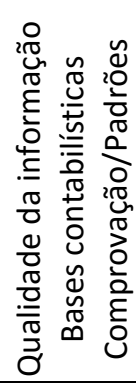 } & & $\begin{array}{l}\text { - As questões centrais (conduta, desempenho, } \\
\text { afirmação, constatação) têm que ser } \\
\text { comprovadas. }\end{array}$ \\
\hline & $\begin{array}{l}\text { - Aceita-se que o cumprimento das bases } \\
\text { conceptuais subjacentes à informação financeira } \\
\text { e das normas de contabilidade geralmente } \\
\text { aceites, aplicadas de uma forma apropriada e } \\
\text { consistente, conduz à apresentação verdadeira e } \\
\text { apropriada das contas da empresa. }\end{array}$ & $\begin{array}{l}\text { - Os padrões de responsabilidade podem ser } \\
\text { estabelecidos por aqueles que são responsáveis. } \\
\text { A conduta atual, o desempenho, etc.. podem ser } \\
\text { avaliados e comparados com estes padrões com } \\
\text { referência a critérios estabelecidos. }\end{array}$ \\
\hline 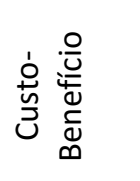 & $\begin{array}{l}\text { - Assume-se que a existência de evidências } \\
\text { suficientes, eficazes e em forma apropriada, } \\
\text { possibilitam ao auditor conduzir uma auditoria } \\
\text { em termos de tempo e custos razoáveis. }\end{array}$ & $\begin{array}{l}\text { - Uma auditoria produz uma vantagem } \\
\text { económico-social. }\end{array}$ \\
\hline 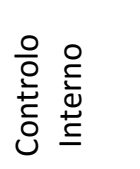 & $\begin{array}{l}\text { - Admite-se que a existência de um bom sistema } \\
\text { de controlo interno afasta, à partida, a } \\
\text { possibilidade da existência de fraudes e erros } \\
\text { relevantes. }\end{array}$ & \\
\hline 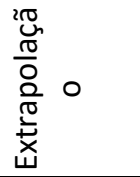 & & \\
\hline
\end{tabular}

Da comparação efetuada constatamos que os postulados justificativos, propostos por Sherer e Kent (1983) e por Flint (1988), baseados nas relações de accountability e na teoria da agência, são mais explorados, pelos primeiros autores, na ótica da credibilidade, atributo que é reforçado por uma auditoria estatutária. Flint (1988), por sua vez, acentua a tónica da responsabilidade e a sua relação com o cumprimento dos padrões estabelecidos a priori, acabando por reconhecer, à semelhança dos anteriores investigadores, que essa afinidade, para ser comprovada, carece de recurso a um processo de auditoria. O pensamento de ambos fertiliza-se mutuamente. A mensagem, no fundo, é idêntica, apesar da narrativa, sob o ponto de vista semântico, ser diferente.

Quanto aos postulados comportamentais, verificamos que Sherer e Kent (1983) comungam de preocupações idênticas aos americanos Mautz e Sharaf (1961), ao admitirem que não existem necessariamente conflitos entre o auditor e a administração sujeita ao exame de auditoria. Sherer e Kent (1983), bem como Flint (1988), apontam a independência como uma característica distintiva da auditoria. Este atributo é considerado condição necessária, mas não suficiente, por estar ligada a um conjunto de competências inerente à função do auditor, a integridade irrepreensível que tem de 
observar e à exigência de uma aptidão especial de exercício de julgamento. Flint (1988), à semelhança de Mautz e Sharaf (1961), acaba por reconhecer que as demonstrações financeiras e toda a informação publicada e sujeita à verificação, está livre de erros intencionais e outras irregularidades. Os postulados funcionais relacionam-se com a evidência, com os padrões de responsabilidade estabelecidos, com a existência de um bom sistema de controlo interno e com a constatação de Flint (1988) que sugere que a auditoria produz valor acrescentado que se traduz numa vantagem económico-social.

Com base nos sistemas postulacionais anteriormente apresentados, elaboramos o seguinte quadro resumo:

Quadro 8 - Resumo dos sistemas postulacionais por autor

\begin{tabular}{|l|c|r|}
\hline \multicolumn{3}{|c|}{ Sherer e Kent } \\
\hline Postulados justificativos & 5 & $38,46 \%$ \\
\hline Postulados comportamentais & 5 & $38,46 \%$ \\
\hline Postulados funcionais & 3 & $23,08 \%$ \\
\hline \multicolumn{3}{|c|}{ Flint } \\
\hline Postulados justificativos & 13 & $100,00 \%$ \\
\hline Postulados comportamentais & 3 & $42,86 \%$ \\
\hline Postulados funcionais & 3 & $42,86 \%$ \\
\hline & 7 & $100,00 \%$ \\
\hline
\end{tabular}

A representação gráfica é a seguinte:

Figura 3 - Número de postulados por autor

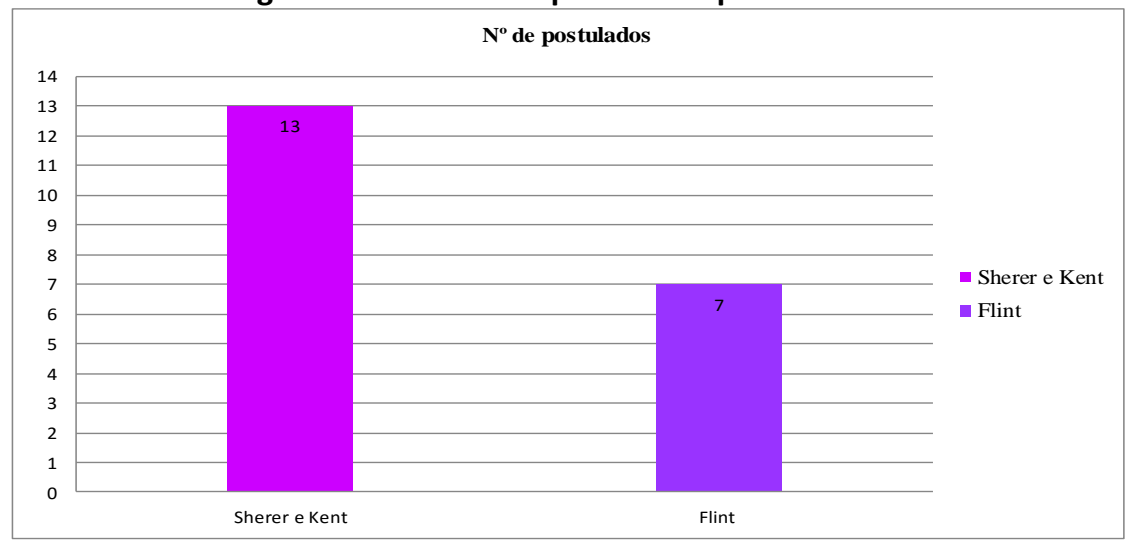

Em termos gráficos, a visualização é a seguinte:

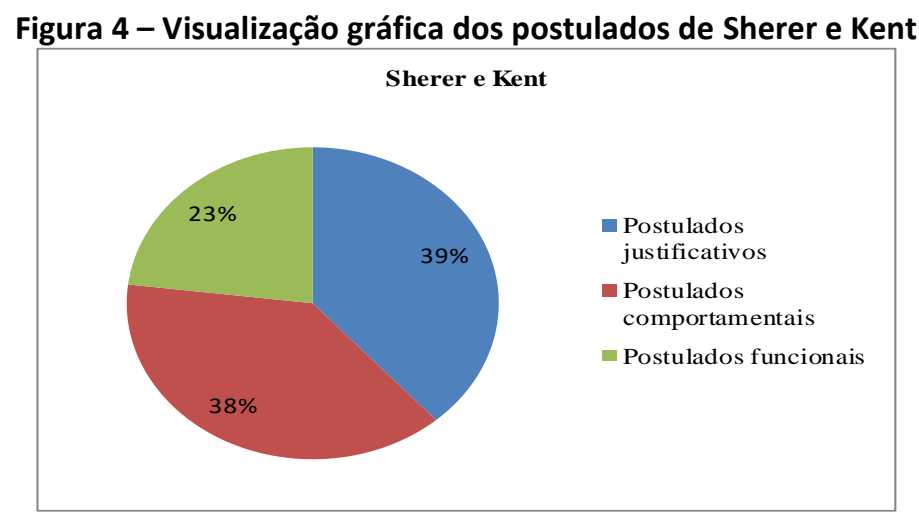




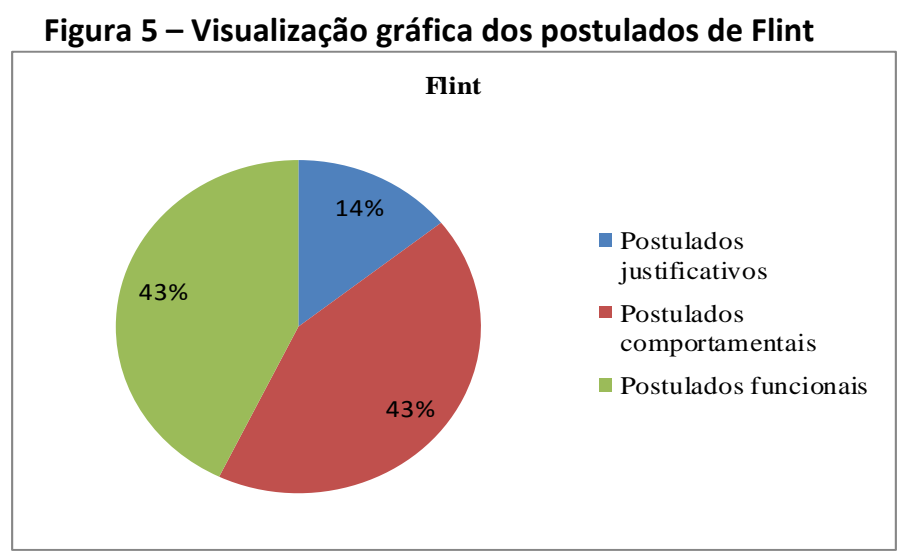

Introduzindo o agregado, obtemos:

Quadro 9 - Resumo agregado dos sistemas postulacionais

\begin{tabular}{|l|c|r|}
\hline \multicolumn{2}{|c|}{ Agregado } \\
\hline Postulados justificativos & 6 & $30,00 \%$ \\
\hline Postulados comportamentais & 8 & $40,00 \%$ \\
\hline Postulados funcionais & 6 & $30,00 \%$ \\
\hline & 20 & $100,00 \%$ \\
\hline
\end{tabular}

As suas representações gráficas assumem as diferentes configurações:

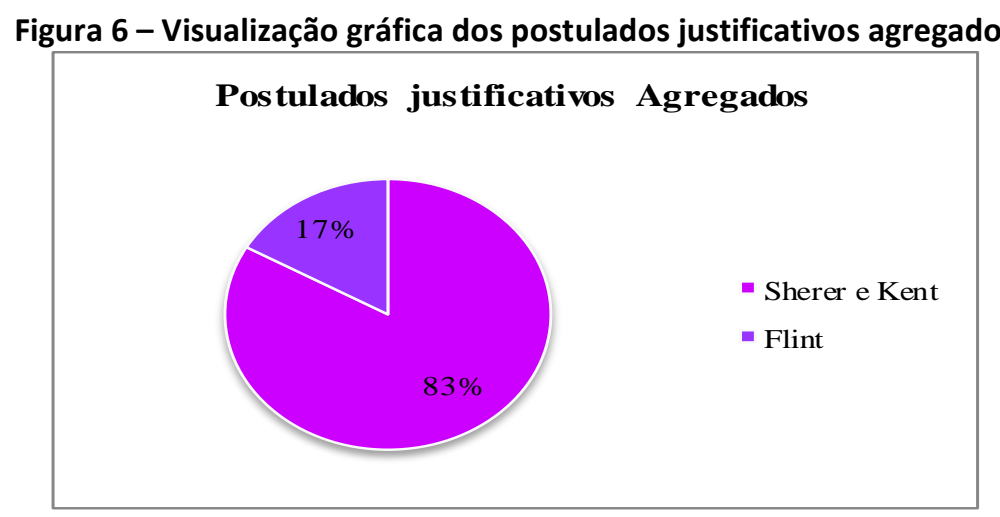

Figura 7 - Visualização gráfica dos postulados comportamentais agregados

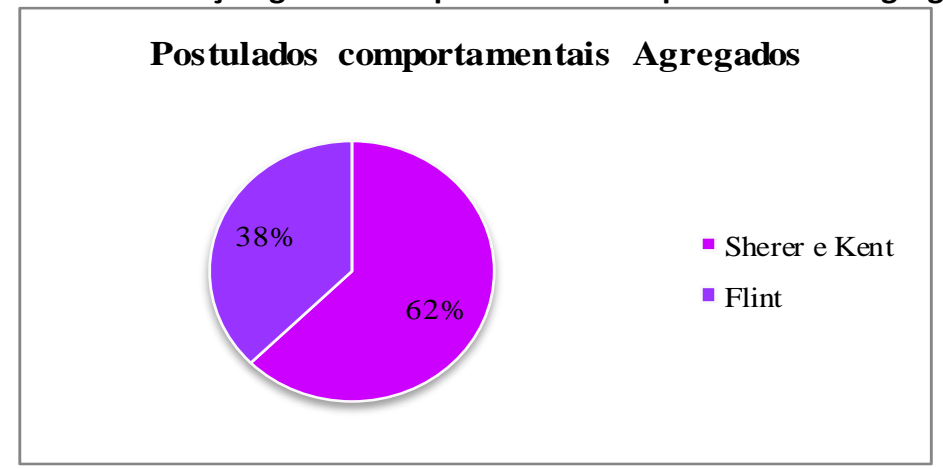


Figura 8 - Visualização gráfica dos postulados funcionais agregados

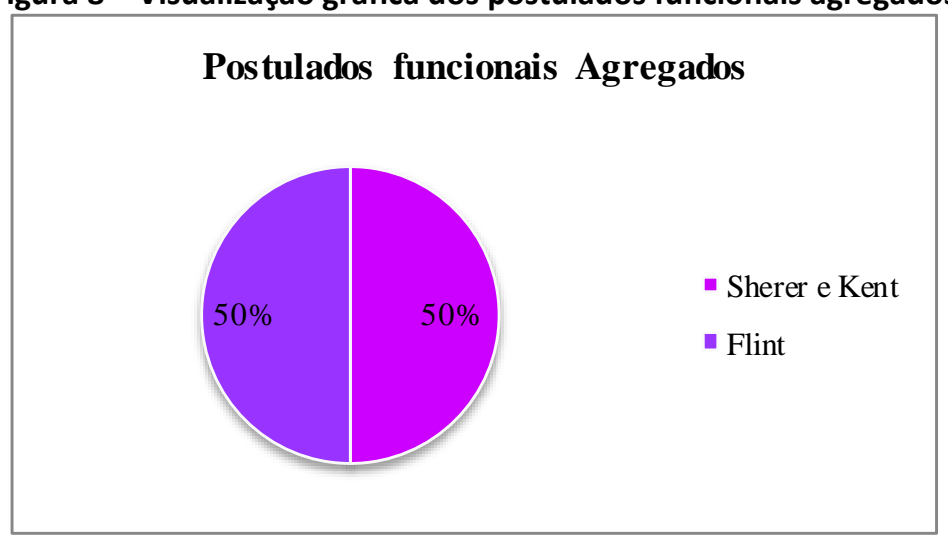

Para axiomatizar a realidade - auditoria - Sherer e Kent (1983) conceberam treze postulados, enquanto Flint (1988) propõe sete postulados. A grande diferença situa-se na categoria dos postulados justificativos, que, no primeiro autor, atinge $38,46 \%$ do total, enquanto no segundo, 14,29\%. Os postulados comportamentais em Sherer e Kent (1983) representam 38,45\% do total, enquanto em Flint (1988), apesar de apresentar um menor número, representam 42,86\% do total. Constatamos, assim, que Sherer e Kent concederam uma maior atenção à justificação da auditoria na sociedade, face ao crescente criticismo de que era alvo, nos anos 80, altura em que o expectation gap ia adquirindo contornos cada veza mais precisos. Relativamente aos postulados funcionais, em termos absolutos, cada autor consagra três informações, com narrativas diferenciadas, que, no fundo, acabam por se completar mutuamente. Se percecionarmos a realidade - a auditoria - de uma forma agregada, concluímos, pela análise do quadro 9 e respetivas representações gráficas, que os postulados justificativos e os postulados funcionais ocupam $60 \%$ do conjunto das afirmações, enquanto os postulados comportamentais ocupam $40 \%$ do total. Concluímos, assim, que os autores atribuem especial importância ao comportamento do auditor. Vejamos, agora, o seguinte quadro:

Quadro 10 - Avaliação das Comparações

\begin{tabular}{|c|c|c|c|c|}
\hline \multirow{2}{*}{ Ordem } & $\begin{array}{c}\text { Sherer Kent } \\
(1983)\end{array}$ & \multirow{2}{*}{ Flint (1988) } & \multicolumn{2}{|c|}{ Avaliação } \\
\cline { 4 - 5 } & & Similar & Divergente \\
\hline 1 & SK1 & F1 & $X$ & \\
\hline 2 & SK2 & F3 & $X$ & \\
\hline 3 & SK3 & F4 & $X$ & \\
\hline 4 & SK4 & F5 & $X$ & \\
\hline 5 & SK5 & F6 & $X$ & \\
\hline 6 & SK6 & F7 & $X$ & \\
\hline 7 & SK7 & F8 & $X$ & \\
\hline 8 & SK8 & F9 & $X$ & \\
\hline 9 & SK9 & F10 & $X$ & \\
\hline 10 & SK10 & F11 & $X$ & \\
\hline 11 & SK11 & F12 & $X$ & \\
\hline 12 & SK12 & F13 & & \\
\hline 13 & SK13 & F14 & $X$ & \\
\hline 14 & SK14 & F15 & $X$ & \\
\hline 15 & SK15 & F16 & $X$ & \\
\hline 16 & SK16 & F17 & $X$ & \\
\hline 17 & SK17 & & & \\
\hline
\end{tabular}


Da avaliação dos dezassete pontos considerados relevantes em ambas as axiomáticas, constatamos uma identificação quase total, com exceção da posição relativamente aos padrões de comparação que são mais restritivos em Sherer e Kent (1983).

\section{DISCUSSÃO}

A escola inglesa propõe para a auditoria, na década de 80, dois sistemas postulacionais importantes baseados na axiomática teórica apresentada pelos autores Sherer e Kent (1983) e Flint (1988). Tratase de uma estrutura lógico-dedutiva mais ampla do que a proposta pelos investigadores norteamericanos Mautz e Sharaf (1961) e Lee (1996), que a delimitaram unicamente à auditoria financeira. A escola inglesa fundamenta-a na relação de accountability, que se traduz numa conduta diligente na afetação de recursos escassos e suscetíveis de emprego alternativo (Sherer e Kent, 1983, p. 9), baseada no pressuposto de que existe uma assimetria de informação entre os agentes e os principais, sendo estes últimos os mais afetados pelo risco de informação.

Esta conceção está de acordo com as ideias de Lee (1996, p. 19), que refere que as incertezas inerentes às contas apresentadas e divulgadas pela empresa têm por base uma multiplicidade de julgamentos subjetivos, que tendencialmente podem afetar os diferentes grupos interessados na atividade da empresa. Esta relação de accountability, na escola inglesa, é bastante mais ampla do que a preconizada pela escola americana, país em que o papel da informação financeira estava dirigido somente para o mercado de capitais. No Reino Unido, porém, a informação financeira é dirigida para todos os stakeholders, aos quais é facultado um conjunto amplo de informação financeira, não financeira e sem base contabilística, que transcende o desenho das demonstrações financeiras tradicionais. A génese das duas abordagens, tão profundamente diferentes, radica nas envolventes social e política às quais o Corporate Report (1975) está intimamente ligado. O enfoque americano reflete uma economia de pendor liberal, enquanto a abordagem inglesa reflete um ambiente político mais social-democrata, exponenciado, no contexto britânico, pelo partido trabalhista que, na altura da apresentação destes sistemas postulacionais, dominava a sociedade inglesa.

Nos Estados Unidos, nos anos 80, o modelo de economia de mercado baseava-se na propriedade privada dos meios de produção e em decisões económicas individuais, visando a obtenção de lucro. Em Inglaterra o objetivo era a satisfação das necessidades sociais, situação que se refletia na informação exigida às empresas: balanço social, mapa de valor acrescentado, etc. Esta conceção tem necessariamente reflexos nos sistemas postulacionais propostos pela escola universitária inglesa, na década de 80 , que se afastaram dos quadros concetuais propostos pelos americanos.

Sherer e Kent (1983, p. 3) e Flint (1988, p. 19-20), tendo em conta o enquadramento socioeconómico existente, propunham ampliar o alcance e o âmbito da auditoria englobando o reporte do value for money das organizações. Nesta sequência, a escola inglesa, quando analisada tendo subjacentes os dezassete pontos considerados relevantes, demonstra, na sua avaliação, uma notável coerência de similitudes de pontos de vista entre ambos os autores. Salienta-se, porém, uma única divergência: a validação do true and fair view (TFV.). De facto, Sherer e Kent (1983, p. 20-027) sugerem que os princípios e normas contabilísticos, quando observados com rigor e de forma consistente, proporcionam uma TFV da entidade auditada, enquanto Flint (1988, p. 19-41), ao referir a avaliação, o desempenho e o benchmarking, está a sugerir outros tipos de comprovação e de avaliação, admitindo, por isso, e sempre, a existência de um critério estabelecido a priori. No SP de Flint (1988, p. 28) a atribuição de responsabilidades aos agentes é uma fase muito importante no processo de accountability, e, neste sentido, a auditoria faz parte do processo de controlo social, cuja característica básica é a afetação e a atribuição de responsabilidades fundamentadas no processo de investigação de evidências. 
Para Flint (1988, p. 12) e Sherer e Kent (1983, p. 9), a ideia de auditoria é adaptativa, na medida em que, como afirmaram Mautz e Sharaf $(1961$, p. 2), a função que o auditor atribui a si próprio pode ser aceite ou rejeitada pela sociedade. A função do auditor na sociedade inglesa dos anos 80 , do século passado, tinha uma estabilidade de atuação que lhe era conferida pela existência de sistemas postulacionais praticamente idênticos, e por um contexto sociopolítico que impôs um modelo de regulamentação empresarial em que o dever de prestação de contas é a sua característica fundamental (Tincker, 1982, p. 58). A realidade de auditoria é observada por Sherer e Kent (1983) através de 13 postulados, sendo 38,46\% afirmações justificativas da auditoria. Por sua vez, Flint (1988) propõe um único axioma. Esta discrepância é, porém, mais semântica do que real: ambos os autores fundamentam a auditoria na chamada teoria da agência. Relativamente aos postulados comportamentais, o quadro legal e as relações entre o auditor e a empresa não são referidos por Sherer e Kent (1983), no entanto, nos domínios da independência, formação e competências, ambos os autores comungam ideias idênticas. Os postulados funcionais propostos apontam a necessidade da existência de padrões de responsabilidade.

No entanto, Sherer e Kent (1983, p. 20-21), como ressalta da análise comparativa efetuada, abordam os princípios e normas contabilísticas, situação que Flint (1988, p. 74) considera demasiado reducionista, e, em consequência, propõe padrões de referência mais amplos. Assim, para axiomatizar a mesma realidade - a auditoria - a escola inglesa apresenta 20 postulados, $65 \%$ dos quais referidos por Sherer e Kent (1983). Estes teóricos sentiram a necessidade de justificar a auditoria num contexto de crescente criticismo da sociedade, período no qual se requeria aos auditores o reporte dos problemas relacionados com a continuidade empresarial e uma maior intervenção na deteção de fraudes e atos ilegais. Contudo, ao nível agregado - escola inglesa verificamos que os postulados justificativos representam, em termos de estrutura percentual, o mesmo que os postulados funcionais, sendo a maior preocupação atribuída aos postulados comportamentais, o que está na linha dos autores da escola americana: Mautz e Sharaf (1961) e Lee (1996). Outra situação que não se observa na escola americana, é a consideração das auditorias internas como suficiente para credibilizar as contas das empresas, que, neste caso, podem ser dispensadas da necessidade de contratar um auditor externo - aspeto relevante 17 , quadro V. Esta faculdade nunca é admitida pela escola americana, que considera a auditoria interna sempre como subsidiária.

Da discussão suscitada anteriormente:

- Validamos parcialmente a H1: porque a avaliação feita no quadro XIII aos dezassete pontos considerados relevantes, aponta para uma única divergência, enquanto as semelhanças são dezasseis, isto é, ao nível de $94,11 \%$ do total.

Validamos a $\mathrm{H} 2$ : porque as funções do auditor na sociedade inglesa, no contexto sociopolítico examinado, sempre consideraram a continuidade da empresa e a deteção de erros e fraudes no âmbito e no alcance da auditoria. A auditoria era considerada um instrumento de controlo social e, portanto, ambas as problemáticas são inseridas legitimamente no âmbito e alcance da auditoria.

Rejeitamos a H3: O número de postulados para explicar a realidade da auditoria varia de autor para autor, quer a nível total, quer, sobretudo, ao nível de número de postulados justificativos.

- Validamos a H4: Ambos os autores concordam em que a existência de uma auditoria interna, independente, dotada de competências e integridade, pode substituir a auditoria externa. 


\section{CONCLUSÕES}

Os sistemas postulacionais propostos por Sherer e Kent (1983) e por Flint (1988) refletem a envolvente sociopolítica dos anos 80 , no Reino Unido, por assimilarem as preocupações sociais, sentidas e percecionadas, à época, pela sociedade inglesa. São, por isso, um notável exemplo do cruzamento perfeito das relações da sociedade com a auditoria. Ambos os autores conferem à auditoria um carácter adaptativo, por não a considerarem como uma variável exógena à sociedade. A fertilização de ambos os sistemas postulacionais é notória e a complementaridade é evidente, muito embora o número de postulados para refletir a realidade seja muito divergente, quando analisados autor a autor. Em termos agregados, ressalta a importância dada aos postulados comportamentais.

Realça-se a importância conferida à auditoria interna independente. Deste modo, esta escola assume que uma auditoria interna dependente de uma forte estrutura de corporate governance pode substituir a auditoria externa. A conceção de auditoria desta escola transcende a auditoria meramente financeira.

\subsection{LIMITAÇÕES DO TRABALHO}

As reduzidas referências efetuadas pelos manuais de auditoria ingleses aos postulados de Sherer e Kent (1983) e de Flint (1988) limita drasticamente a discussão axiomática. Acresce que a submissão dos postulados de Flint (1988) às categorizações de postulados propostos por Sherer e Kent (1983) pode não corresponder exatamente à ideia original do autor, situação suscetível de provocar algumas limitações, ainda que não materialmente relevantes ao trabalho.

\subsection{SUGESTÕES PARA FUTURAS INVESTIGAÇÕES}

A comparação da evolução do pensamento sobre as estruturas concetuais inglesas em confronto com as americanas e outras apresentadas, ao possibilitar o contraste entre visões diferentes, baseadas em sociedades com visões sociopolíticas divergentes, enriqueceria inequivocamente $o$ conteúdo deste trabalho.

\section{REFERÊNCIAS}

Accounting Standards Steering Committee (ASSC). The Corporate Report. London: ASSC, 1975.

Almeida, B. J. M. Auditoria e Sociedade: diferenças de expectativas. Portugal: Publisher Team, 2005.

American Accounting Association (1973). Committee on Basic Auditing Concepts: A Statement of Basic Auditing Concepts. Sarasota, FL: AAA, 1973.

Arens, A. A.; Elder, R. L.; Beasley, M.S. Auditing and Assurance Services: an integrated approach. New Jersey Prentice Hall, 2010.

Berle, A.; Means, G. The modern corporation and private property. New York: MacMillon, 1932.

Elliot, R. K. The future of assurance services: implications for academia. Accounting Horizons, v. 9, n. 4, p. 118-127, 1995.

Financial Accounting Standard Board (FASB). Statement of Financial Accounting Concepts No. 6: Elements of Financial Statements: A Replacement of FASB Concepts Statement No. 3 (incorporating an amendment of FASB Concepts Statement No. 2). Norwalk, CT: FASB, 1985. 
Flint, D. Philosophy and principles of auditing - an introduction. London: The Macmillan Press Ltd, 1988.

International Accounting Standards Board (IASB). Framework for the Preparation and Presentation of Financial. London: IASB, 1989.

Jensen, M. C. Y; Meckling, H. Theory of the firm: managerial behaviour, Agency Costs and Ownership Structure. Journal of Financial Economics, v. 3, n. 4, p. 305-360, 1976.

Johnstone, K.M.; Bedard, J.C. Engagement Planning, Bid Pricing, and Client Response in the Market for Initial Attest Engagements. The Accounting Review, v. 76, n. 2, p. 199-220, 2001.

Knechel, W. Auditing: Assurance \& Risk. 2. Ed. Florida: South-Western College Publishing, 2001.

Lakatos, Eva Maria. Sociologia geral. 4. ed. São Paulo: Atlas, 1981.

Lee, T. Corporate Audit Theory. London: Chapman \& Hall, 1996.

Louwers, T.; Ramsay, R.; Sinason, D.; Thibodeau, J. Auditing \& Assurance Services. 5. ed. New York: McGraw-Hill/Irwin, 2013.

Malinowski, Bronislaw. Argonautas do Pacífico Ocidental. Coleção os Pensadores, Abril, 1978.

Mautz, R.; Sharaf, H. The philosophy of auditing. Florida: American Accounting Association, Sarasota, 1961.

Messier, W.; Glover, S.; Prawitt, D. Auditing \& Assurance Services. 8. ed. New York: McGrawHill/Irwin, 2012.

Molina, G. J. S.; Pérez, M. O. Teoría de la auditoría financiera. McGraw-Hill, 1996.

Pérez, M.; Lara, L. A.; Herrero, J.; Sierra, G. J. Fundamientos Teóricos de La Auditoria Financiera. Madrid: Pirâmide, 2012.

Pérez, M.O., Una Propuesta de Marco Conceptual de la Auditoría de Cuentas Anales. Madrid Instituto de Contabilidad y Auditoría de Cuentas, 1996.

Porter, B.; Gowthorpe, C. Audit expectation-performance gap in the United Kingdom in 1999 and comparison with the Gap in New Zealand in 1989 and in 1999. The Institute of Chartered Accountants of Scotland and Edinburgh, 2004.

Porter, B.; Simon, J.; Hatherly, D.J. Principles of External Auditing. UK: John Wiley \& Sons, 1995.

Porter, W. T.; Burton, J. C. Auditing a conceptual approach. Wadsworth Pub Co, 1970.

Public Company Accounting Oversight Board (PCAOB). An Audit of Internal Control Over Financial Reporting That Is Integrated with an Audit of Financial Statements and Related Other Proposals. Auditing Standard N.o 5. Washington, DC: PCAOB, 2006.

Rahman, M.; McCosh, A. M. The Influence of Organizational and Personal Factors on the Use of Accounting Information: An Empirical Study. Accounting, Organizations and Society, v. 1, n. 4, p. 339-355, 1976.

Ryan, S.; Herz, R.; Iannaconi, T.; Maines, L.; Palepu, K.; Schrand, C.; Skinner, D.; Vincent, L. SEC Auditor Independence Requirements. Accounting Horizons, v. 15, n. 4, p. 7-94, 2001.

Sherer M.; Kent D. Auditing and Accountability. London: Pitman, 1983.

Taylor, M.; DeZoort, T.; Munn, E.; Thomas, M. A Proposed Framework Emphasizing Auditor reliability over Auditor Independence. Accounting Horizons, v. 17, n. 3, p. 257-266, 2003. 
OS POSTULADOS DE AUDITORIA NA ESCOLA UNIVERSITÁRIA INGLESA: UM CRUZAMENTO PERFEITO ENTRE A SOCIEDADE E A AUDITORIA

Tincker, T. Paper Prophets: A social critique of accounting. London: Holt, Rinehart and Winston, 1982.

Weber, M. Economie et société, 1ère partie, Paris: Plon, 1971.

Whittington, R.; Pany, K. Principles of Auditing \& Other Assurance Services. 7. ed. New York: McGraw-Hill/Irwin, 2010. 